\title{
Estrous activity in lactating cows with divergent genetic merit for fertility traits
}

\author{
C. B. Reed, ${ }^{*} \odot$ B. Kuhn-Sherlock, $\odot$ C. R. Burke, $\odot$ and S. Meier $\odot$ \\ DairyNZ Ltd., Private Bag 3221, Hamilton, 3240, New Zealand
}

\begin{abstract}
This observational study aimed to determine the effect of genetic merit for fertility traits on estrous expression and estrous cycle duration in grazing dairy cows, as measured by an activity monitoring device. A secondary aim was to describe changes in expression of estrus that occur during successive estrous cycles postpartum. Neck-mounted, activity-monitoring devices (Heatime, SCR Engineers Ltd.) were fitted to nulliparous Holstein-Friesian heifers with positive (POS FertBV) or negative genetic merit for fertility traits (NEG FertBV) to capture activity data during their first and second lactations (POS FertBV: $\mathrm{n}=242$, $\mathrm{n}$ $=188$; NEG FertBV $: \mathrm{n}=159, \mathrm{n}=87$ in lactation 1 and 2, respectively). An estrous event was identified when the activity change index exceeded 26 activity units (AU) for $4 \mathrm{~h}$. A total of 1,254 and 892 estrous events were identified in lactation 1 and 2, respectively. Estrous duration was defined as the interval between when the threshold was first exceeded and when activity dropped below the threshold, with no new event starting within $24 \mathrm{~h}$ of the end of the previous event. This definition of estrus included cows in which activity crossed the threshold multiple times in a day and were classified as a single estrous event. A second measure, high activity duration, was defined as the total hours that activity exceeded the threshold. To characterize estrous activity, peak activity (above baseline) and total activity (area under the curve of activity above baseline) were measured. Compared with NEG FertBV cows, POS FertBV cows had more active, longer estrous events. In lactation 1, the POS FertBV group had a mean estrous duration and a high activity duration of 12.5 and $12.4 \mathrm{~h}$ compared with 11.4 and $11.3 \mathrm{~h}$ for the NEG FertBV group [standard error of the difference $(\mathrm{SED})=0.5$ and $0.4 \mathrm{~h}$, respectively]. This significant difference also occurred in lactation 2, with a mean
\end{abstract}

Received June 1, 2021.

Accepted October 1, 2021.

*Corresponding author: Charlotte.Reed@dairynz.co.nz estrous duration of 13.1 versus $11.8 \mathrm{~h}(\mathrm{SED}=0.5 \mathrm{~h})$ and a high activity duration of 13.0 versus $11.8 \mathrm{~h}$ (SED $=0.4 \mathrm{~h}$ ) in the POS and NEG FertBV groups, respectively. Total activity and peak activity were greater in the POS compared with the NEG FertBV group in lactation 1 (peak activity: 65.5 vs. 55.8 AU, SED = $2.4 \mathrm{AU}$; total activity: 588 vs. $494 \mathrm{AU}, \mathrm{SED}=25 \mathrm{AU}$ ) and lactation 2 (peak activity: 72.5 vs. $61.2 \mathrm{AU}$, SED $=2.9 \mathrm{AU}$; total activity: 648 vs. $541 \mathrm{AU}, \mathrm{SED}=30$ AU). Estrous cycle duration did not differ between the POS and NEG FertBV groups (lactation 1: 20.4 vs. $20.6 \mathrm{~d}, \mathrm{SED}=0.25$; lactation $2: 20.8$ vs. $21.0 \mathrm{~d}$, SED $=0.28$ ). Less estrous activity of the cow was associated with the first postpartum estrus. In contrast, the number of previous estrous events did not consistently affect the duration of the subsequent estrous cycle. The outcomes of this study provide evidence that positive genetic merit for fertility traits is associated with more overt estrous expression. Selection for these traits may improve estrous expression and thus estrous detection in commercial herds.

Key words: estrus, reproduction, activity monitors, behavior

\section{INTRODUCTION}

Effective estrous detection in dairy cows is required to maintain a high level of reproductive performance. Artificial insemination accounts for most breeding events in dairy cows, and the success of AI programs depends upon the farmers' ability to identify cows in estrus and correctly time insemination to maximize the chance of conception. Thus, errors in estrous detection can limit the reproductive performance of the herd. Poor estrous detection is a result of 2 types of errors (Xu and Burton, 1996). The first error relates to issues with the sensitivity of detection, characterized by missing cows in estrus during the breeding period. The consequences within a seasonal calving herd manifest in the subsequent lactational season with later calving and lost milk production. The second error relates to the specificity of estrous detection, when cows not in estrus are inseminated. Not only does this incur the 
costs associated with insemination, but if the cow was already pregnant, it will substantially increase the risk of pregnancy failure (Macmillan et al., 1977; Sturman et al., 2000).

Fertility traits have previously been associated with more overt signs of estrus in dairy cows. Irish dairy cows selected for good (Fert+, representative of the top $20 \%$ of Irish dairy cows for fertility genetics) genetic merit for fertility traits were reported to have shorter estrous cycles and more estrous activity than those with poor (Fert-, representative of the bottom $5 \%$ of Irish dairy cows for fertility genetics) genetic merit for fertility (Cummins et al., 2012b). A positive association between estrous characteristics and some fertility traits has been reported in US dairy heifers following estrous synchrony (Veronese et al., 2019a). A recent study in New Zealand indicated that dairy cows with positive genetic merit for fertility traits have shorter postpartum anestrus and a greater likelihood of being submitted to AI during the first $6 \mathrm{wk}$ of the breeding period compared with dairy cows with negative genetic merit for fertility traits (Burke et al., 2018; Meier et al., 2021a). Therefore, based on associations of fertility genetics and estrous characteristics reported previously, it is plausible that the greater submission rates in dairy cows with positive, compared with negative, genetic merit for fertility traits may occur because of differences in the intensity (i.e., more or less active) or duration of estrous behavior.

Intensity and duration of estrous behavior may also be influenced by the number of ovulations that have occurred since the cow resumed estrous cycles after parturition. The intensity and duration of estrous behavior is reported to increase from the first to second postpartum estrus (Nyman et al., 2018; Zebari, 2019). Less progesterone (P4) exposure before ovulation or possibly a refractoriness to estradiol are thought to cause less intense estrous behaviors before the first or second cycle (Nyman et al., 2018). This phenomenon has important implications in seasonal systems, whereby some cows may have a relatively short postpartum interval before the start of breeding, and, therefore, they may be bred on their first or second estrus (McNaughton et al., 2007).

We hypothesized that cows with positive genetic merit for fertility traits will have more active and longer estrous expression and shorter estrous cycles than those with negative genetic merit for fertility traits. We also hypothesized that estrous behavior will become more overt with successive postpartum ovulations. The main objective of this study was to compare estrous activity and duration, and estrous cycle duration in grazing dairy cows in New Zealand with positive (POS
FertBV) or negative genetic merit for fertility traits (NEG FertBV) during their first and second lactations. A secondary aim was to describe the effect of successive postpartum ovulations on estrous behavior traits.

\section{METHODS AND MATERIALS}

\section{Animals}

This study was undertaken in 2017 through 2019 in the Waikato, New Zealand, with the approval of the Ruakura Animal Ethics Committee (AE application \#14200). Activity data were collected from 523 Holstein-Friesian dairy cows during their first and second lactations. These cows were representative of 2 genetic groups, divergent for fertility traits but with comparable average breeding values for milk volume, fat, protein, BW, and North American ancestry (Table 1). The herd was established in 2015 through a targeted breeding program whereby suitable dams were identified on commercial dairy farms and bred to sires with extreme POS FertBV or NEG FertBV to produce calves with either POS FertBV or NEG FertBV. The female calves born from this breeding program were kept under the same management from $4 \mathrm{~d}$ of age, as previously described (Meier et al., 2021a,b). In the current study, the cows were managed as a typical commercial herd of grazing cows under a spring-calving system, in which cows calved between June and September and were managed on pasture throughout the transition and lactation periods. Cows rotationally grazed pasture that was composed predominantly of perennial ryegrass (Lolium perenne L.) and white clover (Trifolium repens L.) as described by Roche et al. (2007). Cows were milked twice daily and had access to a fresh allocation of pasture following each milking. The breeding period began on October 9 in both lactations and lasted $85 \mathrm{~d}$ in lactation 1 and $77 \mathrm{~d}$ in lactation 2 .

\section{SCR Heatime System}

All cows were fitted with a neck-collar activity device (Heatime, SCR Engineers Ltd.) before their first calving that was capable of identifying activity-based estrous events. These devices contain an accelerometer that quantifies activity (arbitrary units; AU) and have been validated for estrous detection in grazing cattle (Aungier et al., 2012; Talukder et al., 2015). Data from the activity devices were wirelessly transmitted to base unit receivers connected to a computer (Aungier et al., 2012; SCR Engineers, 2015). The base unit was positioned in the milking shed so data were downloaded 
from the collars at least twice a day and could be accessed from the farm computer during lactation.

\section{Data Files and Exclusions}

For this study, reports containing raw activity and the activity change index (a SCR system variable that captures the difference in raw activity from an individual's baseline, weighted by the SD) and cow information data were exported from the Heatime system into Excel (Microsoft Office 365 ProPlus; Microsoft Corp.). Comma-separated values (CSV) files containing data from the SCR reports on all cows for the first 245 calving season days (CSD) from each lactation were compiled and merged into 1 file per lactation. Calving season day was equal to the number of days past June 1 in that calving year. This was calculated for both lactation 1 and 2 and is used as a standardized way to describe the timing of events during the 2 lactations and later in statistical models to account for different calendar dates.

The 2 CSV files containing all data for each lactation were imported into $\mathrm{R}$ separately for analysis ( $\mathrm{R}$ Core Team, 2020). Cow EBV, calving, breeding, and conception records were imported and matched with the activity data by cow, and where applicable, by date. For analysis, data for each cow were limited to the period between the first postpartum week and the end of the breeding period. Raw activity and activity change data in this range were checked for completeness. When data for a single 2-h time block were missing, missing activity values were imputed using an average of the value from the preceding and subsequent time block. Cows missing consecutive 2-h time blocks of data were removed from the data set.

Table 1. Breeding values for genetic indices of nulliparous HolsteinFriesian heifers with positive (POS FertBV) or negative genetic merit for fertility traits $(\mathrm{NEG} \text { FertBV })^{1}$; means $\pm \mathrm{SD}$ are presented

\begin{tabular}{lcc}
\hline Breeding value $(\mathrm{BV})^{2}$ & $\begin{array}{c}\text { POS FertBV } \\
(\mathrm{n}=275)\end{array}$ & $\begin{array}{c}\text { NEG FertBV } \\
(\mathrm{n}=248)\end{array}$ \\
\hline BCS BV & $0.07 \pm 0.07$ & $-0.08 \pm 0.07$ \\
Fertility BV, \% & $4.99 \pm 0.74$ & $-5.12 \pm 1.36$ \\
Inbreeding coefficient, $\%$ & $2.64 \pm 1.23$ & $3.05 \pm 1.62$ \\
BW BV, kg & $36.81 \pm 12.49$ & $39.72 \pm 10.04$ \\
Milk fat BV, kg & $11.27 \pm 5.46$ & $17.84 \pm 6.57$ \\
Milk protein BV, kg & $19.9 \pm 3.48$ & $23.25 \pm 4.58$ \\
Milk volume BV, L & $653.87 \pm 165.07$ & $731.48 \pm 157.86$ \\
North American HF $\%^{3}$ & $56.01 \pm 6.23$ & $62.02 \pm 8.42$ \\
\hline
\end{tabular}

${ }^{1}$ POS FertBV refers to dairy heifers with positive $(+5.0$ average) fertility breeding value. NEG FertBV refers to heifers with a negative $(-5.1$ on average) fertility breeding value.

${ }^{2}$ Breeding values derived from the New Zealand Animal Evaluation (NZAEL) animal evaluation run date February 2017 (Meier et al., 2021a).

${ }^{3}$ Percentage of North American Holstein-Friesian (HF) ancestry.

\section{Detection of Ovulation}

Individual milk P4 concentration was measured twice weekly during lactation 1 and once weekly during lactation 2 from calving until the end of the sixth week of the breeding period as described by Meier et al. (2021a). Briefly, milk samples were collected during milking and stored at $-20^{\circ} \mathrm{C}$ until further processing. Thawed samples were centrifuged at $4^{\circ} \mathrm{C}, 1,900 \times g$ for $12 \mathrm{~min}$ to collect the skim milk. Progesterone concentrations in the skim milk were determined using a double antibody RIA kit (ImmuChem Progesterone Double Antibody RIA, MP Diagnostics) as per the manufacturer's instructions. The performance parameters of this assay have been previously reported (Meier et al., 2021a). Briefly, the mean concentration \pm standard deviation was $4.08 \pm 1.58 \mathrm{ng} / \mathrm{mL}$ for the high standard, 1.76 $\pm 0.33 \mathrm{ng} / \mathrm{mL}$ for the medium standard, and $0.79 \pm$ $0.18 \mathrm{ng} / \mathrm{mL}$ for the low standard. The interassay and intra-assay coefficients of variation were 11.3 and $7.5 \%$ for the high standard, 11.5 and $4.3 \%$ for the medium standard, and 12.1 and $9.2 \%$ for the low standard. The minimal detectable concentration of the assay was 0.44 $\mathrm{ng} / \mathrm{mL}$. In total, 9,281 samples were assayed over 19 assays in lactation 1 , and 2,705 samples were assayed over 16 assays in lactation 2 .

Milk P4 data were used to identify ovulation windows between samplings when ovulation had occurred, and non-ovulatory windows when $\mathrm{P} 4$ remained high. An ovulation window was triggered by a low milk $\mathrm{P} 4$ concentration $(<0.44 \mathrm{ng} / \mathrm{mL})$ followed by an elevated $\mathrm{P} 4$ concentration $(>0.55 \mathrm{ng} / \mathrm{mL})$ in either of the 2 subsequent milk samples (Figure 1). The cut point of $0.55 \mathrm{ng} / \mathrm{mL}$ was chosen as it has been demonstrated to correspond with a plasma concentration of $1 \mathrm{ng} /$ $\mathrm{mL}$ (Meier et al., 2021a). When triggered, ovulation windows were extended from the day after the previous elevated P4 sample until the day before the next elevated P4 sample to include all days when ovulation may have occurred. A good example of this method is cow 1 in Figure 1, which shows ovulation windows at regular intervals, whereas cow 3 did not resume cycling during $\mathrm{P} 4$ sampling. An ovulatory window was not triggered by a marginal $\mathrm{P} 4$ concentration (0.44-0.55 ng/ $\mathrm{mL}$ ) followed by a sample $>0.55 \mathrm{ng} / \mathrm{mL}$ (Figure 1 ; cow 2).

\section{Identifying Estrous Events}

As ovulation is likely to be preceded by estrous expression, we used the ovulatory windows described previously to determine a threshold activity change to identify estrous events. The receiver operator characteristic (ROC) curve analysis was used to determine the 
activity change threshold and duration of this threshold that best distinguished between an ovulatory and nonovulatory window. In this analysis, activity change was used as the independent variable and ovulation (as determined by milk P4) as the outcome variable. The pROC package (Robin et al., 2011) was used to create ROC curves in $\mathrm{R}$ to test the ability of the highest 4 or $6 \mathrm{~h}$ of consecutive activity change values recorded during each window to predict if it was an ovulatory or nonovulatory window (i.e., what is the greatest activity
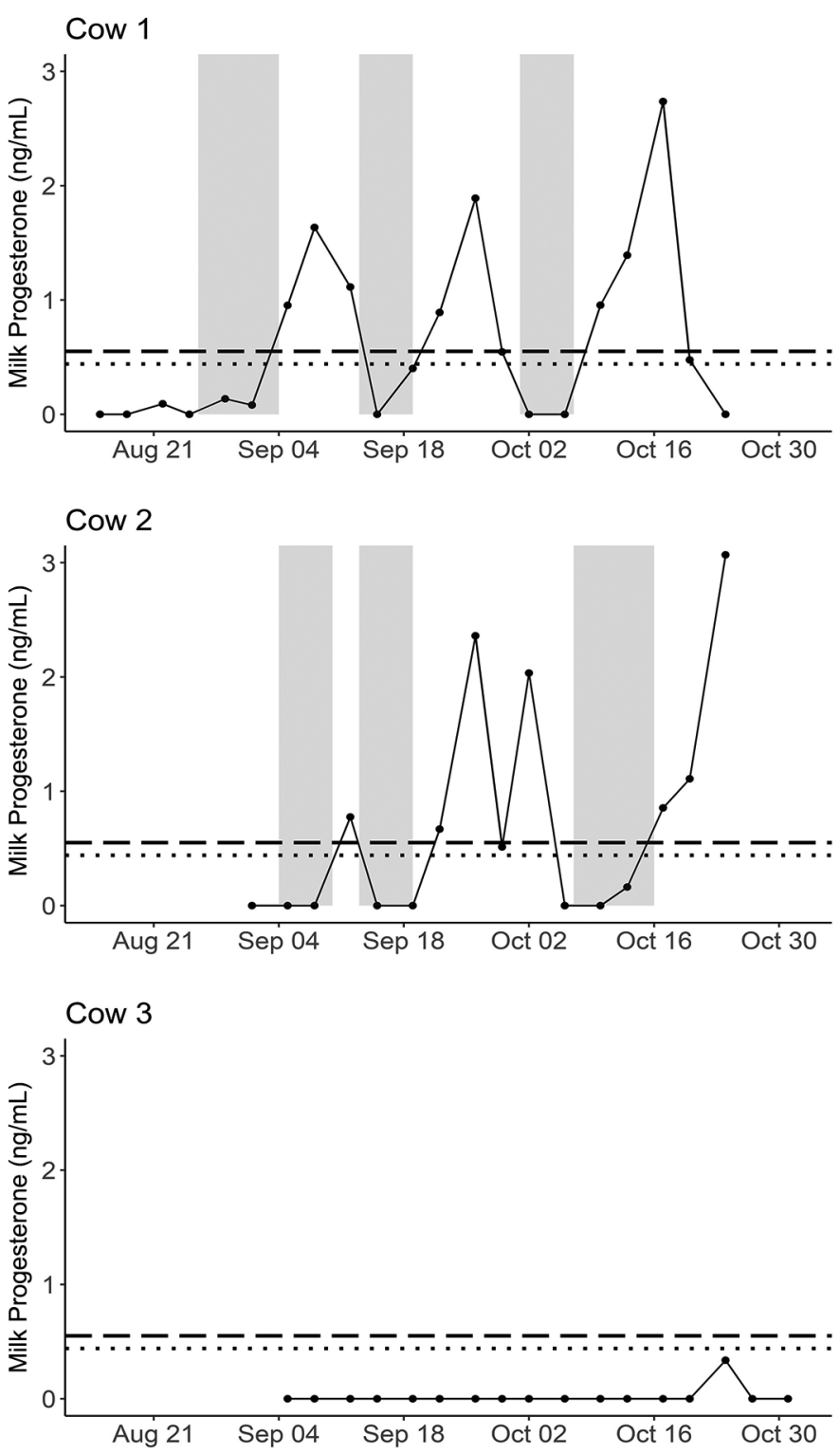

Figure 1. Skim milk progesterone $(\mathrm{ng} / \mathrm{mL})$ concentrations in 3 cows, showing ovulatory (shaded) and nonovulatory (nonshaded) windows. The threshold for a high $\mathrm{P} 4$ result $(0.55 \mathrm{ng} / \mathrm{mL})$ is shown by the dashed horizontal line; the dotted line immediately below represents the minimum detectable concentration $0.44 \mathrm{ng} / \mathrm{mL}$ that was used as a cut-off for marginal samples.

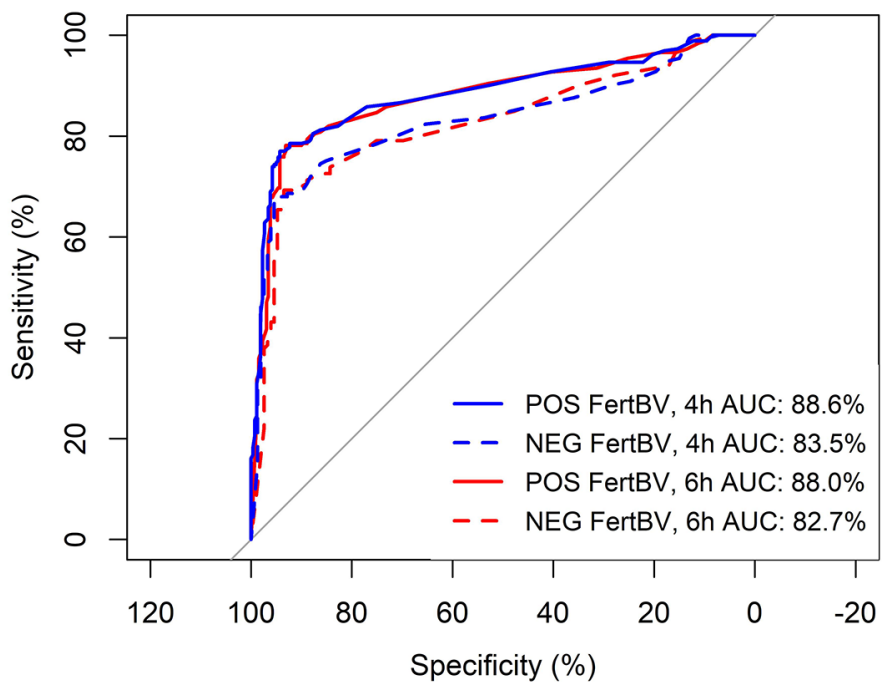

Figure 2. Receiver operating characteristic curves showing the ability of the maximum value for activity change, a variable generated by SCR Heatime system (SCR Engineers Ltd.), to discriminate between ovulatory and nonovulatory windows in lactating dairy cows. The 2 models tested used maximum activity change over 4 (blue) or 6 (red) consecutive hours to identify an ovulation window. Receiver operator characteristic curves were generated separately for cows with extreme positive (POS FertBV) or negative (NEG FertBV) fertility breeding value. Areas under the curve (AUC) for each model and fertility group are shown on the figure.

change threshold that will trigger an estrous alert in that window?). As a large proportion of first, and to a lesser extent, second ovulations, are not preceded by estrous activity (Isobe et al., 2004), data associated with postpartum anestrus, and the first or second ovulation window (based on milk P4 records) were excluded from this procedure. A threshold of activity change $\geq 26 \mathrm{AU}$ for $4 \mathrm{~h}$ was selected based on its specificity and sensitivity for detecting ovulation in both POS and NEG FertBV cows (Figure 2).

This threshold was used to determine estrous events in the entire lactation 1 and 2 data sets. Activity events occurring within the breeding period were matched to insemination events and their conception outcome. To match an estrous event to an insemination date, the date of estrous onset had to coincide with the date of the insemination, or 1 calendar d either side of the date of insemination. Any events occurring more than $10 \mathrm{~d}$ before the first rise in milk $\mathrm{P} 4$ following calving were removed as these are most likely false positives occurring during postpartum anestrus. When an estrous alert occurred during $10 \mathrm{~d}$ before the first postpartum elevated milk P4 was detected, the incidence was recorded and compared between fertility groups. If a cow had 2 events occurring within $7 \mathrm{~d}$, it was assumed at least 1 event was false. Matching insemination dates, milk $\mathrm{P} 4$ records and matching SCR high activity events 


\section{Lactation 1}

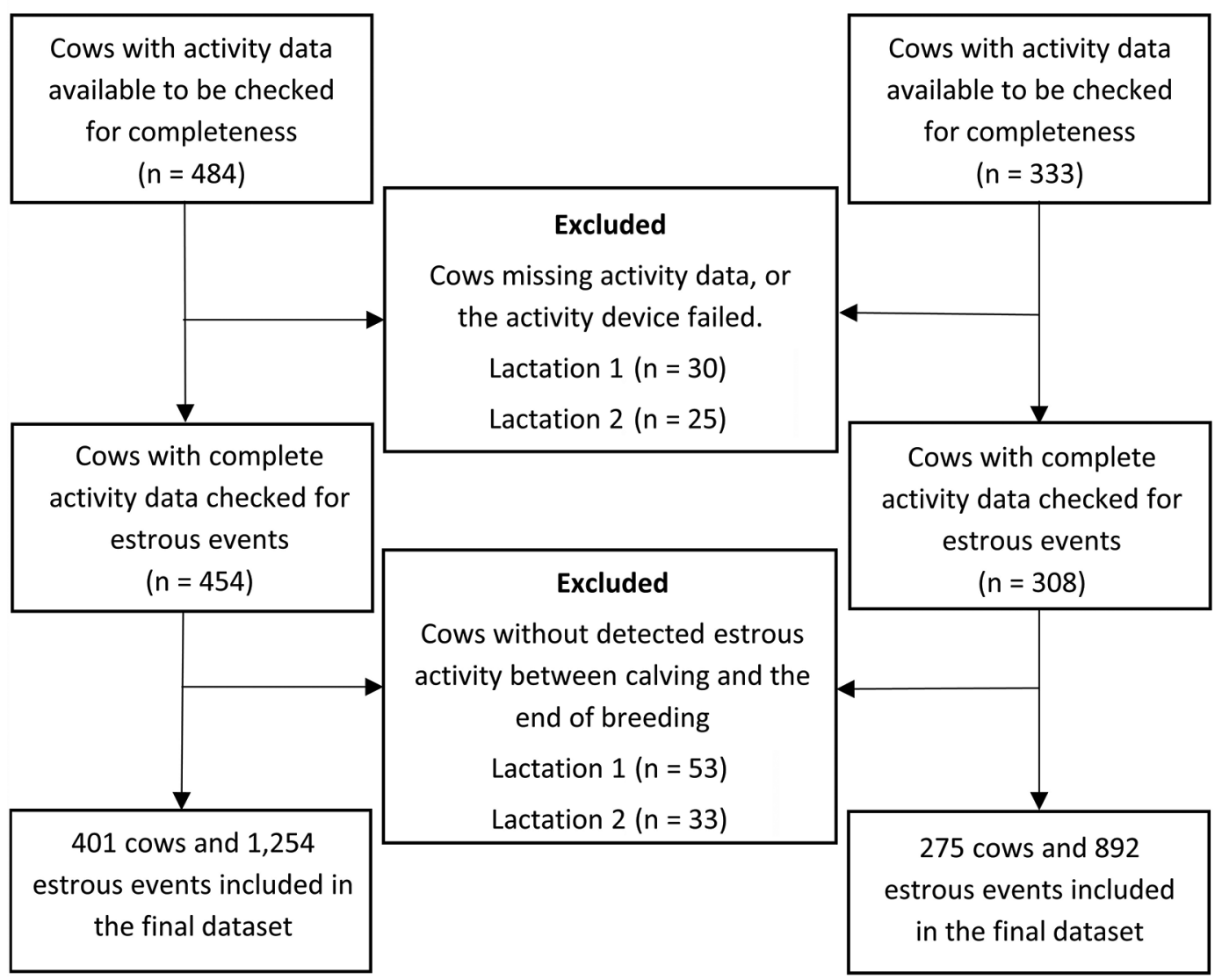

Figure 3. Consort diagram of cow inclusion into the final data set for lactations 1 and 2 .

were used, in that order, to distinguish between the genuine and false event and the false event was removed. Cows with complete data but no estrous events did not contribute to the final data set (Figure $3 ; \mathrm{n}=$ 53 in lactation $1, \mathrm{n}=33$ in lactation 2 ). The final lactation 1 data set comprised 1,254 estrous events from 401 cows and the lactation 2 data set comprised 892 estrous events from 275 cows (Figure 3).

\section{Estrous Behavior Variables}

We investigated estrous intensity (how active the cow was), duration of estrus, and estrous cycle duration (d). Duration of estrus was defined using activity change data. Initially, estrous duration was defined as the time a cow's activity change was above the estrous activity threshold (e.g., $\geq 26$ AU for 4 h). However, during some estrous events, the activity change dropped below the threshold for 1 or more time blocks before rising and triggering a second estrous alert. To account for these events, any estrus starting within $24 \mathrm{~h}$ of the end of the previous estrous event was considered part of the first event. Estrous duration was defined as the interval between when the activity threshold was first exceeded and when activity dropped below the threshold, with no new event starting within $24 \mathrm{~h}$ of the end of the first alert. A second variable, high activity (HA) duration, was created to capture differences between the activity of a cow that remained above threshold for the entire estrous event and those that did not. This was defined as the time that cow activity was above threshold during an estrous event.

Two measures of the intensity of estrous activity were defined using raw activity data. First, a baseline for raw activity was calculated from the cow's activity data from the $7 \mathrm{~d}$ preceding the estrous alert. Peak activity was equal to the maximum raw activity value minus baseline activity recorded during an estrous event. Total activity was equal to the area under the curve of raw activity during the estrous event when raw activity was subtracted from baseline activity. The area under the curve was calculated as the positive incremental 
area using the trapezoidal rule. The interestrous interval (IEI) was calculated as the number of days between the onset of 2 consecutive estrous events.

\section{Numbering Postpartum Estrous Events}

Postpartum estrous events for each cow were numbered in the order they were detected, and this variable was called "estrous event number." However, the first postpartum ovulation is often not accompanied by behavioral estrus, a phenomenon termed "silent estrus." Therefore, estrous event number 1 corresponded with the first ovulation in some cows but the second ovulation in others. To account for this, if the first postpartum ovulation (as detected by a subsequent rise in milk P4) had no corresponding estrous event, estrous events were numbered from 2 upwards. If there was an estrous event corresponding to the first rise in milk P4, events were numbered from 1 upwards.

\section{Statistical Analyses}

Statistical analyses were undertaken using SAS 9.4 (SAS Institute Inc.). To investigate the associations between estrous variables or estrous cycle duration and fertility group (POS and NEG FertBV), estrous event number, and their interactions, a repeated measures ANOVA was undertaken (PROC MIXED and PROC HPMIXED, SAS). The model included fertility group, estrous event number, and their interaction as fixed effects, calving season day as a covariate, and random effect of cow. A first order autoregressive covariance structure, $\operatorname{AR}(1)$, was used. Tukey's test was used for pairwise comparisons of estrous event numbers.

Using this model, 3 different analyses were undertaken using either (1) all estrous events; or (2) only events that occurred before the start of the breeding period; or (3) within the first 6 wk of the breeding period. The analysis only included estrous event numbers where data from 10 or more cows of each FertBV group was available. Analysis of IEI was run twice, including then excluding intervals outside a physiological range of 14 to $28 \mathrm{~d}$. Excluding very long and very short intervals reduces the risk of faulty detection of estrus. This technique has been applied previously when IEI or interservice intervals were used to investigate estrous cycle duration in cows (Greenham et al., 2019).

A mixed effects model was used to investigate the effects of fertility group, conception outcome (whether the cow did or did not conceive following insemination) and AI number on estrous characteristics. The model included fertility group, conception outcome, insemination number and all 2-way interactions as fixed effects, calving season day as a covariate, and cow as a random effect. Tukey's test was used for pairwise comparisons of AI numbers. This analysis differed from our breeding period analysis in that only estrous events with an associated insemination record were included.

The proportion of first ovulations not accompanied by an increase in estrous activity was compared between fertility groups using a binary logistic regression. The model included group as a fixed effect and calving season day as a covariate. All cows with complete data were used in this analysis, except for $1 \mathrm{cow}$ in lactation 1, who was excluded as she had no records of milk P4, (lactation $1: \mathrm{n}=453$. lactation $2: \mathrm{n}=308$ ).

\section{RESULTS}

\section{All Estrous Events}

The estrous events of the POS FertBV group had greater total and peak activity and a longer duration than those of the NEG FertBV group in both lactation 1 and 2 (Table 2). Estrous event number affected estrous duration and estrous activity in both lactations, whereby HA duration, estrous duration, and total and peak estrous activity increased from the first estrus compared with subsequent events $(P<0.01$ for all variables; Table 2). The IEI was not different between fertility groups or estrous event numbers when the events were limited to a physiological range (14-28 d). When all events were included, IEI was affected by estrous event number $(P=0.02, P<0.01$, in lactation 1 and 2 respectively; Table 2$)$ but not fertility group $(P=0.48$, $P=0.18$, in lactation 1 and 2 respectively; Table 2 ), where the IEI between the first and second estrus was shorter than that between the second and third estrus, but not different from subsequent IEI.

\section{Estrous Events Before Planned Start of Breeding}

When the data were restricted to events occurring before the planned start of the breeding period, total and peak estrous activity were greater in the POS FertBV cows compared with the NEG FertBV cows. This difference occurred in both lactation $1(P=0.02$ for both peak and total activity) and $2(P<0.01, P=$ 0.01 for peak and total activity, respectively). Estrous event number affected estrous activity and peak in both lactations $(P<0.01$ for all variables; Supplemental Table S1, http://dx.doi.org/10.17605/OSF.IO/T2743; Reed and Meier, 2021), as the first estrus had consistently less total and peak estrous activity. There was a significant interaction between fertility group and estrous event number for both high activity duration and estrous duration in lactation $1(P=0.05$ and $P=0.02$, respectively; Supplemental Table S1). This interaction 
Reed et al.: ESTROUS TRAITS AND GENETIC FERTILITY IN COWS

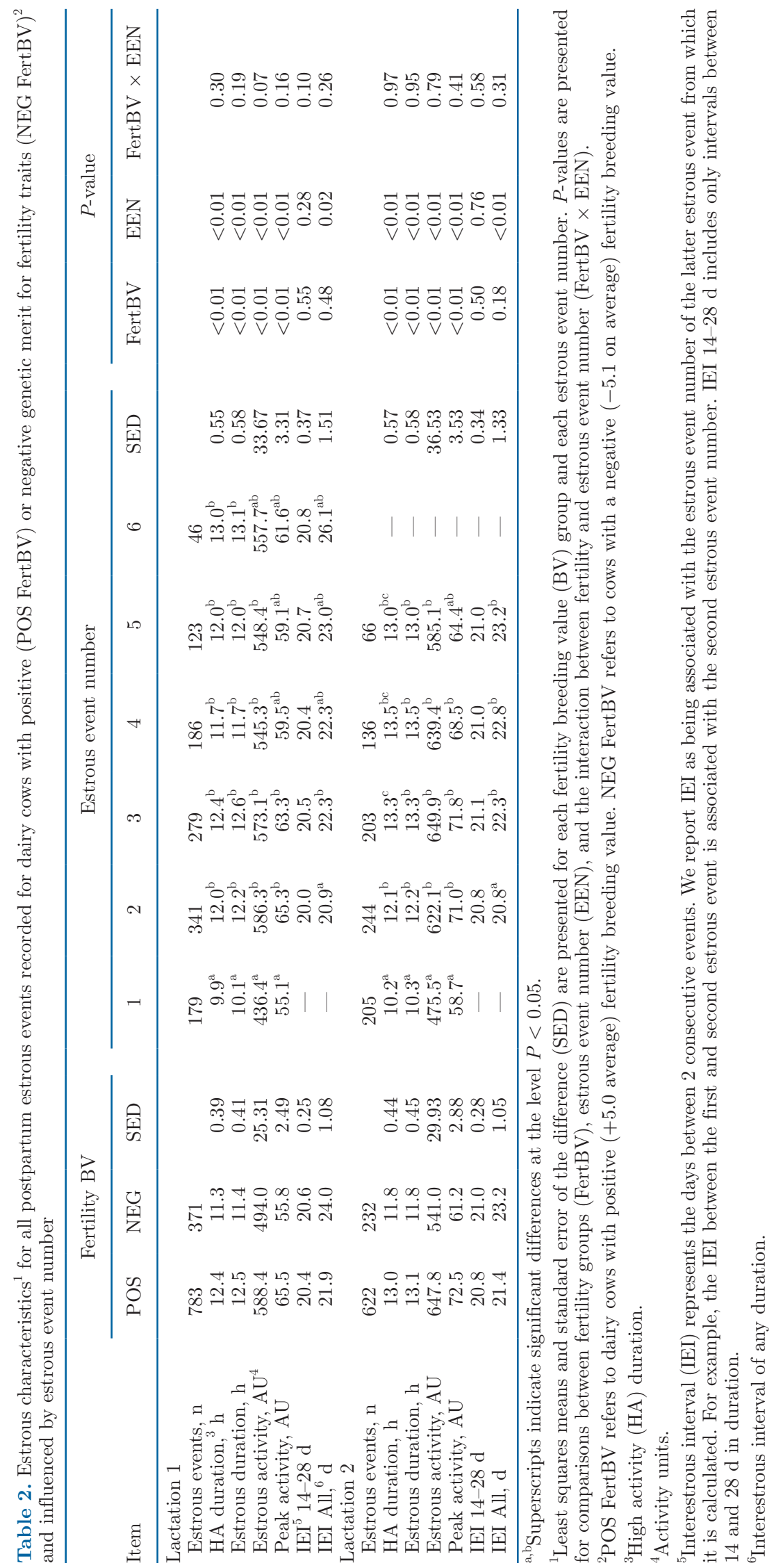


indicated that cows in the POS FertBV group had a greater HA duration and estrous duration in their first 2 estrous events postpartum compared with cows in the NEG FertBV group, but no further differences occurred at subsequent estrous events (Supplemental Figure S1, http://dx.doi.org/10.17605/OSF.IO/T2743; Reed and Meier, 2021).

In lactation 2, the POS FertBV cows had longer estrous events (HA duration and estrous duration, both $P<0.01$ ). Both HA duration and estrous duration were shorter for the first postpartum estrous event compared with subsequent estrous events. $(P<0.01$ for all variables; Supplemental Table S1). High activity duration and estrous duration were shorter $(P<0.01$ and $P=0.03$, respectively) in the second estrus compared with the third estrus. There was no interaction between fertility and estrous event number for any of the estrous characteristics during lactation 2 (Supplemental Table S1). Estrous event number affected IEI (including all events) in lactation 1 only $(P=0.01)$, whereby the IEI between the first and second estrus was significantly shorter than subsequent intervals.

\section{Estrous Events After Planned Start of Breeding}

When the data were limited to events occurring in the first 6 wk of breeding, estrous activity and peak were greater in the POS FertBV cows compared with the NEG FertBV cows (Supplemental Table S2, http:/ /dx.doi.org/10.17605/OSF.IO/T2743; Reed and Meier, 2021). This result occurred in lactation 1 (both $P<$ $0.01)$ and $2(P=0.02$ and $P=0.03$ for peak and total activity). Estrous event number affected both variables in lactation 1 only (both $P<0.01$ ). Estrous duration and high activity duration differed between fertility groups and estrous event numbers in lactation 1 only $(P<0.01$ for all variables), whereby they were longer in the POS FertBV cows and shorter in the first estrous event compared with subsequent estrous events. There were significant main effects of fertility group $(P=0.04)$ and estrous event number $(P=0.05)$ and their interaction $(P<0.01)$ on IEI; however, only in lactation 1 . This occurred as the POS-FertBV groups had a longer IEI between the first and second estrus compared with the NEG-FertBV group $(P<0.01)$ but did not differ between subsequent events (Supplemental Figure S2, http://dx.doi.org/10.17605/OSF.IO/T2743; Reed and Meier, 2021). In lactation 2, only estrous event number was significant for this variable $(P<0.01$; Supplemental Table S2), where IEI tended to decrease with increasing estrous event number. When IEI was limited to a physiological range (14-28 d) neither estrous event number nor fertility groups, or their interactions were significant.

\section{Estrous Characteristics and Conception}

No estrous characteristics differed between events that did or did not result in conception following AI. There were no significant interactions between conception and fertility group for any of the estrous characteristics investigated (Table 3). In lactation 1, cows were more active (total and peak activity) during estrous events associated with the first insemination, compared with those associated with the second insemination (both $P<0.01$ ). In contrast, total, and peak activity was intermediate at the third insemination and not different from the first or second insemination. The effect of fertility group on each estrous characteristic were largely consistent with our breeding period analysis.

\section{Proportion of First Ovulations Without Estrous Events}

The proportion of cows having first ovulations postpartum not accompanied by an estrous event was greater in the NEG compared with POS FertBV group in lactation 1 (adjusted mean proportion 0.50 POS vs. $0.60 \%$ NEG, $P=0.04$, odds ratio $=0.67: 95 \%$ CI: $0.46-0.97)$. The groups did not differ in lactation 2 (adjusted mean proportion 0.30 POS vs. 0.34 NEG, $P$ $=0.50)$.

\section{DISCUSSION}

As accurate estrous detection is essential to achieve a high level of reproductive performance in seasonal breeding dairy herds, it is desirable for cows to display obvious estrous behavior. This study used activity monitor data to investigate the relationship between estrous characteristics and the New Zealand fertility breeding value. Furthermore, the data allowed the comparison of estrous intensity, duration, and IEI interval at successive postpartum estrous events and events that did or did not result in conception. The outcomes of this study provide compelling evidence that FertBV of the cow and the number of estrous cycles postpartum affect the expression of estrous behavior.

\section{Genetic Merit for Fertility Traits}

We found that cows with positive genetic merit for fertility traits have longer, more active estrous events than those with negative genetic merit for fertility traits, but estrous cycle duration did not differ between the 2 groups. Overall, peak estrous activity was $18 \%$ greater in the POS FertBV group compared with the NEG FertBV group. This finding is supported by Cum- 
Reed et al.: ESTROUS TRAITS AND GENETIC FERTILITY IN COWS

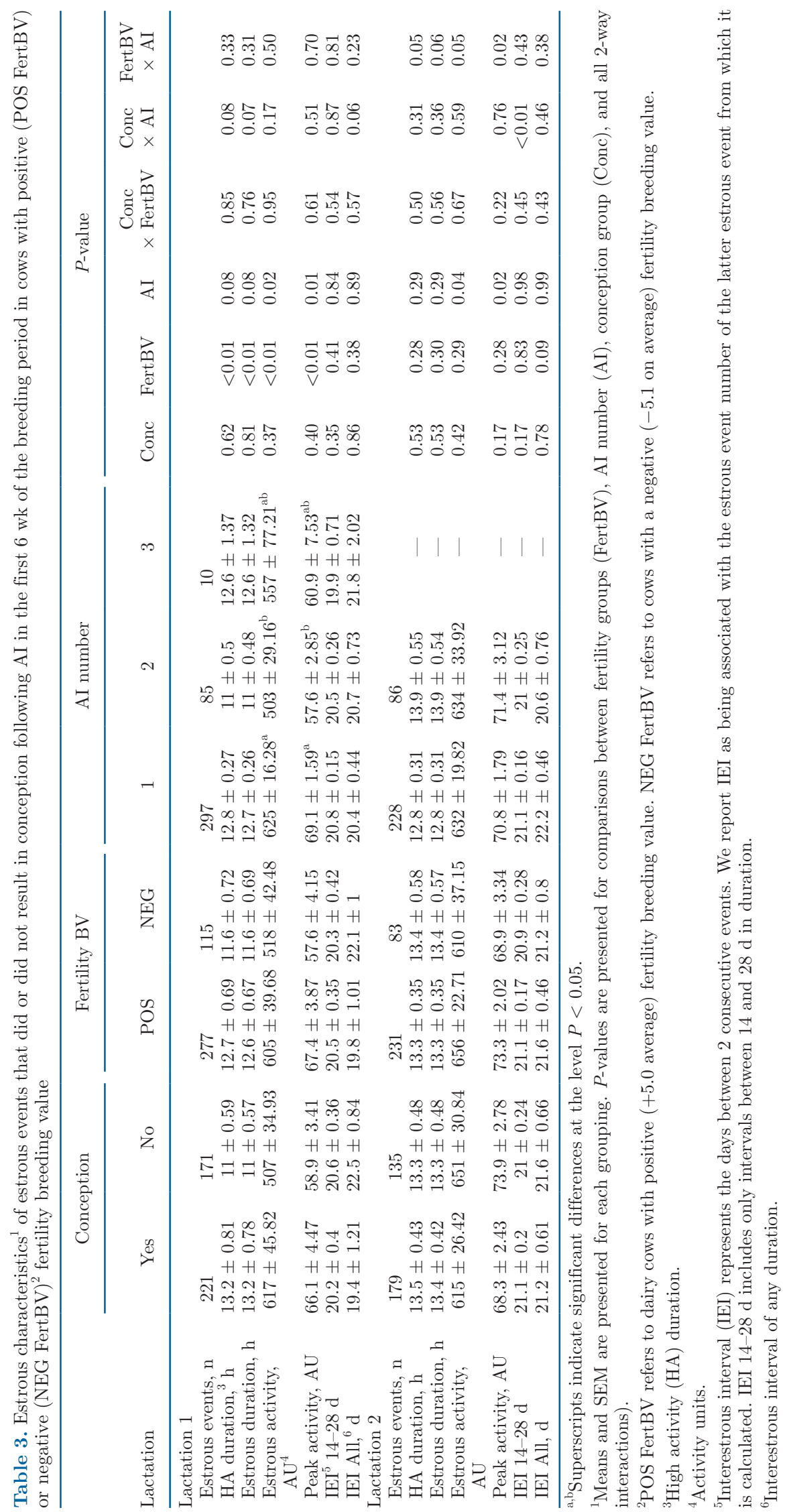


mins et al. (2012b) who reported a $41 \%$ increase in peak estrous activity in a similar study using Irish dairy cows with good (Fert+) or poor (Fert-) genetic merit for fertility traits. In lactation 1 , the difference between fertility groups was even greater during the breeding period $(24 \%)$ but less pronounced before the breeding period $(10 \%)$. In lactation 2 , the differences between fertility groups were similar both before (14\%) and during the breeding period (13\%).

Total estrous activity was overall $20 \%$ greater in the POS FertBV cows, indicating not only did they have a greater peak activity, but they were more active during the entire estrous event. Other aspects of estrous activity, time in standing estrus and the number of standing events, have been positively associated with circulating estradiol concentration (Lopez et al., 2004). Plasma estradiol was not measured in our study, but a difference in circulating concentrations at the time of estrus may underlie the differences between the POS and NEG FertBV cows. Circulating estradiol is positively associated with genetic merit for fertility traits in Irish dairy cows (Moore et al., 2014) and in North American Holstein heifers (Veronese et al., 2019b). In contrast, Cummins et al. (2012b) did not find a significant difference in plasma estradiol in the Fert+ and Fert- research herd despite a difference in peak estrous activity. Estrous intensity is also affected by body condition and milk production (Lopez et al., 2004). However, as milk production and body condition have been previously reported as not different between the POS and NEG FertBV groups, these factors do not seem to be driving the difference between the fertility groups (Meier et al., 2021a). The mechanisms underlying the greater estrous intensity of the POS FertBV cows remain unclear, but possible differences in plasma estradiol at estrus should be investigated further in the POS-NEG model.

Cows with POS FertBV had longer estrous events. When all events were included in the analysis, cows with POS FertBV had 1.1 and $1.3 \mathrm{~h}$ longer estrous events in lactation 1 and 2, respectively, compared with cows in the NEG FertBV group. This difference was even larger during the breeding period of lactation 1, $2.1 \mathrm{~h}$, although less pronounced between events occurring before the breeding period. This trend was reversed in lactation 2 whereby the difference between fertility groups was more pronounced in events occurring before the breeding period than those occurring in the first 6 wk of breeding.

Again, this result is consistent with Cummins et al. (2012b) who reported a difference of $1.6 \mathrm{~h}$ in Irish Fert+ compared with Fert- dairy cows. In contrast, Veronese et al. (2019a) found that US dairy heifers with high genomic merit for heifer conception rate had shorter spontaneous estrous events. Although the heifers with high genomic merit for another fertility trait, daughter pregnancy rate, had longer estrous activity following synchronized estrus, but not at spontaneous estrus. Longer estrous events were also reported in primiparous cows with high genomic merit for daughter pregnancy rate (Chebel and Veronese, 2020). This disparity is likely the result of the different fertility traits used and their dependency on estrous detection. The US trait, heifer conception rate, is an estimate of the probability of conception following insemination and does not account for estrous expression or submission, although it would require insemination to be correctly timed. Daughter pregnancy rate is a measure of pregnancy risk during a 21-d period. This measure is calculated from days open and accounts for a voluntary waiting period following calving during which cows are not eligible for breeding. Estrous expression may contribute to this trait as the cow must be identified and submitted to conceive. Similarly, the Irish fertility index used by Cummins et al. (2012b) relies on the predictor trait calving interval, which also requires the cow to be correctly submitted for AI to avoid long intervals between calvings (Cummins et al., 2012a). The New Zealand FertBV used in this study relies on the predictor trait, 3-wk submission, which estimates the likelihood the cow will be submitted to breeding within 3 wk of the breeding period (DairyNZ, 2019). Therefore, selection for appropriate estrous behavior is somewhat inherent in these indices. As submission for breeding is a predictor trait for the New Zealand FertBV, it makes sense that there are clear associations between estrous characteristics and the FertBV.

There were few differences in the IEI between the POS and NEG FertBV groups. When IEI were limited to a physiological range, there were no differences between fertility groups. Without excluding these extreme events there was a difference between fertility groups in events occurring during the first 6 wk of breeding in their first lactation only. This may have been caused by different rates of missed or silent estrous events or embryonic loss between fertility groups during this period. Our findings are not consistent with the Irish model, as the Fert- cows had abnormally long estrous cycles (25 d on average), which differed significantly from the Fert+ cows (21 d on average; Cummins et al., 2012b). These previous authors discussed reported associations in the literature between cycle length, number of follicular waves per cycle, and fertility outcome. These reported associations, however, are not relevant to our findings where estrous cycle lengths were of normal length and not different between fertility groups.

The fertility advantage of cows with POS FertBV may be increased further by incorporating estrous traits into the FertBV. Wearable activity monitors automati- 
cally collect large quantities of data that have the potential to be used for genetic selection. Researchers in in Denmark (Løvendahl and Chagunda, 2009; Ismael et al., 2015) and Norway (Aglen, 2019) have already used activity monitor data to investigate the heritability and variability of estrous traits. A select group of commercial herds in Australia are used to intensively monitor the health and performance of the cows to inform breeding values and bull selection (Pryce et al., 2018). Implementing a similar system would provide opportunities to use activity-based traits to advance the fertility of dairy cows. Therefore, it would be useful to explore the genetic basis and heritability of activitybased estrous traits such as those described in this study, in New Zealand dairy cows.

\section{Number of Estrous Events Postpartum}

Estrous intensity and duration increased with subsequent postpartum estrous events. The biggest increases occurred between the first, second, and third estrous events. A similar effect has been reported in UK dairy cows; estrous duration and peak activity were less in the first estrus and overall activity less in the first and second postpartum estrus compared with subsequent cycles (Zebari, 2019). Less active estrous expression in first and second postpartum cycles may occur because of reduced exposure to P4 before ovulation. Greater circulating $\mathrm{P} 4$ concentrations in the cycle preceding estrus have been associated with more intense behavioral estrus (Callahan et al., 1971; Schams et al., 1978; Kyle et al., 1992). Concentrations of $\mathrm{P} 4$ are baseline before first postpartum ovulation, and the corpus luteum that forms from this first ovulation produces less $\mathrm{P} 4$ than in subsequent cycles (Kawashima et al., 2006; Nyman et al., 2018). Therefore, the cow is likely exposed to lesser $\mathrm{P} 4$ concentrations before the first and second ovulation, resulting in less intense estrous behavior. Milk production in early lactation may affect estrous intensity. High milk volumes produced in early lactation have been associated with greater hepatic blood flow and faster metabolism of steroids, reducing circulating estradiol (Sangsritavong et al., 2002; Lopez et al., 2004). A clear negative association between milk production and estrous duration has been reported (Lopez et al., 2004). Greater milk production may be associated with less active estrous expression in early lactation than in subsequent cycles. It has also been proposed that exposure to elevated estradiol concentrations during late pregnancy induces a refractory state, so the cow becomes less responsive to estradiol for a period of time after calving (Allrich, 1994). This would also result in less active estrous behavior before early postpartum ovulations. In New Zealand, industry guidelines recommend at least $75 \%$ of the herd are cycling at the beginning of breeding (DairyNZ, 2021). Our data support this recommendation, so most cows will show strong estrous signs during the breeding period.

The number of previous estrous cycles did not affect IEI when these intervals were limited to a physiological range. In contrast, when all intervals were included, there was a significant effect of estrous event number on IEI. This may indicate that the number of first ovulations without estrus activity or estrous detection inaccuracies is affected by number of postpartum cycles. This is consistent with our finding that estrous activity and duration are also affected by estrous event number. Furthermore, short cycles are more common following the first postpartum ovulation because of premature regression of the corpus luteum (Peter et al., 1989). Early postpartum estrous events associated with short estrous cycles also contribute to a difference in IEI as the postpartum estrous events increase.

\section{Conception and Estrous Characteristics}

We did not find an association between any estrous characteristics and conception to AI. This is inconsistent with previous studies that report a positive association between estrous intensity or peak activity and conception rate (Madureira et al., 2015; Nyman et al., 2016). The lack of association in our study suggests estrous traits and conception traits could be selected separately. However, the lack of significance is more likely due to lack of statistical power.

\section{Estrus at the First Postpartum Ovulation}

The proportion of first ovulations not accompanied by an estrous event differed between fertility groups in lactation 1 but not 2. The POS FertBV group were $33 \%$ more likely to display estrus activity at the first postpartum ovulation. This result is consistent with the overall better reproductive outcomes seen in the POS FertBV group relative the NEG FertBV group. Furthermore, we observed a marked difference in the incidence of failure to express estrous behavior between lactations. As primiparous cows, more than half of the herd did not have an activity-detected estrous event at the postpartum ovulation. In contrast, in their second lactation, this dropped to roughly $30 \%$. The first rise in milk $\mathrm{P} 4$, indicating first ovulation, may have been missed more frequently in lactation 2 as milk samples were collected once weekly rather than twice weekly as in lactation 1. This would increase the likelihood a first ovulation with estrus activity was mislabeled, decreasing their prevalence in lactation 2. Alternatively, parity or season may have a marked effect of the incidence of 
estrous express at the first postpartum ovulation, but this study was not designed to investigate these effects.

\section{CONCLUSIONS}

Overall, this study provides evidence estrous event lactating dairy cows with positive genetic merit for fertility traits have longer estrus and are more active during the estrous event than cows with negative genetic merit for fertility traits. Furthermore, estrous intensity and duration increase with successive postpartum estrous cycles. In contrast, the duration of the estrous cycle does not seem to be consistently affected by either the cow's fertility breeding value or number of previous postpartum cycles. Furthermore, estrous activity did not differ between estrous events that did or did not lead to conception. These findings provide insights into the physiological differences driving the divergent fertility of POS and NEG FertBV cows. We have also confirmed the beneficial effect of repeated postpartum estrous cycles on estrous expression in lactating, grazing dairy cows.

\section{ACKNOWLEDGMENTS}

This project was funded by a partnership (DRCX1302) between the New Zealand Ministry of Business, Innovation and Employment, and New Zealand dairy farmers through DairyNZ Inc. (CB1804). The authors gratefully acknowledge the technical assistance of the DairyNZ technical team in data collection, particularly Jenny Brown for analyzing milk progesterone samples and Dagmar Elliot for maintaining the activity collars. The authors also acknowledge the AgResearch Tokanui Farm staff for their assistance throughout the trial. The authors have not stated any conflicts of interest.

\section{REFERENCES}

Aglen, J. 2019. New activity-based fertility traits for Norwegian Red dairy cattle: Definitions, heritabilities and comparison to traditional fertility traits. MS thesis. Department of Animal and Aquacultural Sciences, Norwegian University of Life Sciences, Ås, Norway.

Allrich, R. D. 1994. Endocrine and neural control of estrus in dairy cows. J. Dairy Sci. 77:2738-2744. https://doi.org/10.3168/jds .S0022-0302(94)77216-7.

Aungier, S. P. M., J. F. Roche, M. Sheehy, and M. A. Crowe. 2012. Effects of management and health on the use of activity monitoring for estrus detection in dairy cows. J. Dairy Sci. 95:2452-2466. https://doi.org/10.3168/jds.2011-4653.

Burke, C., C. Phyn, S. Meier, S. Turner, A. Heiser, S. Edwards, and J. Roche. 2018. Solutions to improve fertility and lifetime productivity in dairy herds. Pages 57-66 in Proceedings of the South Island Dairy Event Conference. South Island Dairy Event, Dunedin, New Zealand. South Island Dairy Event (SIDE).

Callahan, C. J., R. E. Erb, A. H. Surve, and R. D. Randel. 1971. Variables influencing ovarian cycles in postpartum dairy cows. J. Anim. Sci. 33:1053-1059. https://doi.org/10.2527/jas1971.3351053x.
Chebel, R. C., and A. Veronese. 2020. Associations between genomic merit for daughter pregnancy rate of Holstein cows and metabolites postpartum and estrus characteristics. J. Dairy Sci. 103:10754-10768. https://doi.org/10.3168/jds.2020-18207.

Cummins, S. B., P. Lonergan, A. C. O. Evans, D. P. Berry, R. D. Evans, and S. T. Butler. 2012a. Genetic merit for fertility traits in Holstein cows: I. Production characteristics and reproductive efficiency in a pasture-based system. J. Dairy Sci. 95:1310-1322. https://doi.org/10.3168/jds.2011-4742.

Cummins, S. B., P. Lonergan, A. C. O. Evans, and S. T. Butler. 2012b. Genetic merit for fertility traits in Holstein cows: II. Ovarian follicular and corpus luteum dynamics, reproductive hormones, and estrus behavior. J. Dairy Sci. 95:3698-3710. https://doi.org/ 10.3168/jds.2011-4976.

DairyNZ. 2019. Interpreting the info: Breeding Values. Accessed Jan. 23, 2019. https://www.dairynz.co.nz/animal/animal-evaluation/ interpreting-the-info/breeding-values/.

DairyNZ. 2021. Observing cows to detect heats. Accessed Mar. 30, 2021. https://www.dairynz.co.nz/animal/reproduction-and -mating/heat-detection/observing-cows-to-detect-heats/.

Greenham, T., G. Oikonomou, and D. H. Grove-White. 2019. A description of interestrus and interservice intervals and associated fertility in 16 United Kingdom dairy herds. J. Dairy Sci. 102:824832. https://doi.org/10.3168/jds.2018-14755.

Ismael, A., E. Strandberg, M. Kargo, A. Fogh, and P. Løvendahl. 2015. Estrus traits derived from activity measurements are heritable and closely related to the time from calving to first insemination. J. Dairy Sci. 98:3470-3477. https://doi.org/10.3168/jds.2014-8940.

Isobe, N., T. Yoshimura, C. Yoshida, and T. Nakao. 2004. Incidence of silent ovulation in dairy cows during post partum period. Dtsch. Tierarztl. Wochenschr. 111:35-38.

Kawashima, C., E. Kaneko, C. Amaya Montoya, M. Matsui, N. Yamagishi, N. Matsunaga, M. Ishii, K. Kida, Y. Miyake, and A. Miyamoto. 2006. Relationship between the first ovulation within three weeks postpartum and subsequent ovarian cycles and fertility in high producing dairy cows. J. Reprod. Dev. 52:479-486. https:// doi.org/10.1262/jrd.18003.

Kyle, S. D., C. J. Callahan, and R. D. Allrich. 1992. Effect of progesterone on the expression of estrus at the first postpartum ovulation in dairy cattle. J. Dairy Sci. 75:1456-1460. https://doi.org/10 .3168/jds.S0022-0302(92)77901-6.

Lopez, H., L. D. Satter, and M. C. Wiltbank. 2004. Relationship between level of milk production and estrous behavior of lactating dairy cows. Anim. Reprod. Sci. 81:209-223. https://doi.org/10 .1016/j.anireprosci.2003.10.009.

Løvendahl, P., and M. G. G. Chagunda. 2009. Short communication: Genetic variation in estrus activity traits. J. Dairy Sci. 92:46834688. https://doi.org/10.3168/jds.2008-1736.

Macmillan, K. L., E. D. Fielden, and R. J. Curnow. 1977. VIII. Effects of non-oestrous inseminations and return patterns after second inseminations. N. Z. J. Exp. Agric. 5:123-127. https://doi.org/10 .1080/03015521.1977.10425950.

Madureira, A. M. L., B. F. Silper, T. A. Burnett, L. Polsky, L. H. Cruppe, D. M. Veira, J. L. M. Vasconcelos, and R. L. A. Cerri. 2015. Factors affecting expression of estrus measured by activity monitors and conception risk of lactating dairy cows. J. Dairy Sci 98:7003-7014. https://doi.org/10.3168/jds.2015-9672.

McNaughton, L. R., K. M. Sanders, J. E. Pryce, G. E. Bracefield, S. J. Harcourt, and R. J. Spelman. 2007. Phenotypic relationships between the interval from calving to first luteal activity and fertility in a seasonal dairy production system. Anim. Reprod. Sci. 102:98-110. https://doi.org/10.1016/j.anireprosci.2006.10.014.

Meier, S., B. Kuhn-Sherlock, P. A. Amer, J. R. Roche, and C. R. Burke. 2021a. Positive genetic merit for fertility traits is associated with superior reproductive performance in pasture-based dairy cows with seasonal calving. J. Dairy Sci. 104:10382-10398. https:/ /doi.org/10.3168/jds.2021-20195.

Meier, S., L. R. McNaughton, R. Handcock, P. R. Amer, P. R. Beatson, J. R. Bryant, K. G. Dodds, R. Spelman, J. R. Roche, and C. R. Burke. 2021b. Heifers with positive genetic merit for fertility traits reach puberty earlier and have a greater pregnancy rate than 
heifers with negative genetic merit for fertility traits. J. Dairy Sci. 104:3707-3721. https://doi.org/10.3168/jds.2020-19155.

Moore, S. G., S. Scully, J. A. Browne, T. Fair, and S. T. Butler. 2014. Genetic merit for fertility traits in Holstein cows: V. Factors affecting circulating progesterone concentrations. J. Dairy Sci. 97:5543-5557. https://doi.org/10.3168/jds.2014-8133.

Nyman, S., H. Gustafsson, and B. Berglund. 2018. Extent and pattern of pregnancy losses and progesterone levels during gestation in Swedish Red and Swedish Holstein dairy cows. Acta Vet. Scand. 60:68. https://doi.org/10.1186/s13028-018-0420-6.

Nyman, S., S. E. Malm, H. Gustafsson, and B. Berglund. 2016. A longitudinal study of oestrous characteristics and conception in tiestalled and loose-housed Swedish dairy cows. Acta Agric. Scand. A Anim. Sci. 66:135-144. https://doi.org/10.1080/09064702.2017 .1313306

Peter, A. T., W. T. Bosu, R. M. Liptrap, and E. Cummings. 1989. Temporal changes in serum prostaglandin F2alpha and oxytocin in dairy cows with short luteal phases after the first postpartum ovulation. Theriogenology 32:277-284. https://doi.org/10.1016/ 0093-691X(89)90318-X.

Pryce, J. E., T. T. T. Nguyen, M. Axford, G. Nieuwhof, and M. Shaffer. 2018. Symposium review: Building a better cow-The Australian experience and future perspectives. J. Dairy Sci. 101:37023713. https://doi.org/10.3168/jds.2017-13377.

R Core Team. 2020. R: A Language and Environment for Statistical Computing. R Foundation for Statistical Computing, Vienna, Austria.

Reed, C. B., and S. Meier. 2021. Estrus activity in lactating cows with divergent genetic merit for fertility traits. https://doi.org/10 $.17605 /$ OSF.IO/T2743

Robin, X., N. Turck, A. Hainard, N. Tiberti, F. Lisacek, J. C. Sanchez, and M. Müller. 2011. pROC: An open-source package for R and $\mathrm{S}+$ to analyze and compare ROC curves. BMC Bioinformatics 12:77. https://doi.org/10.1186/1471-2105-12-77.

Roche, J. R., K. A. Macdonald, C. R. Burke, J. M. Lee, and D. P. Berry. 2007. Associations among body condition score, body weight, and reproductive performance in seasonal-calving dairy cattle. J. Dairy Sci. 90:376-391. https://doi.org/10.3168/jds.S0022 -0302(07)72639-5.

Sangsritavong, S., D. K. Combs, R. Sartori, L. E. Armentano, and M. C. Wiltbank. 2002. High feed intake increases liver blood flow and metabolism of progesterone and estradiol-17beta in dairy cattle. J. Dairy Sci. 85:2831-2842. https://doi.org/10.3168/jds.S0022 -0302(02)74370-1.
Schams, D., E. Schallenberger, C. Menzer, J. Stangl, K. Zottmeier, B. Hoffmann, and H. Karg. 1978. Profiles of LH, FSH and progesterone in postpartum dairy cows and their relationship to the commencement of cyclic functions. Theriogenology 10:453-468. https: //doi.org/10.1016/0093-691X(78)90135-8.

SCR Engineers. 2015. The SCR Heatime HR system. Accessed Jul. 8, 2019. http://www.scrdairy.com/cow-intelligence/heatime-hr -system.html.

Sturman, H., E. A. B. Oltenacu, and R. H. Foote. 2000. Importance of inseminating only cows in estrus. Theriogenology 53:1657-1667. https://doi.org/10.1016/S0093-691X(00)00305-8.

Talukder, S., P. C. Thomson, K. L. Kerrisk, C. E. F. Clark, and P. Celi. 2015. Evaluation of infrared thermography body temperature and collar-mounted accelerometer and acoustic technology for predicting time of ovulation of cows in a pasture-based system. Theriogenology 83:739-748. https://doi.org/10.1016/j.theriogenology .2014.11.005.

Veronese, A., O. Marques, R. Moreira, A. L. Belli, R. S. Bisinotto, T. R. Bilby, F. Peñagaricano, and R. C. Chebel. 2019a. Genomic merit for reproductive traits. I: Estrous characteristics and fertility in Holstein heifers. J. Dairy Sci. 102:6624-6638. https://doi.org/10 .3168/jds.2018-15205.

Veronese, A., O. Marques, F. Peñagaricano, R. S. Bisinotto, K. G. Pohler, T. R. Bilby, and R. C. Chebel. 2019b. Genomic merit for reproductive traits. II: Physiological responses of Holstein heifers. J. Dairy Sci. 102:6639-6648. https://doi.org/10.3168/jds.2018 -15245 .

Xu, Z., and L. Burton. 1996. Reproductive efficiency in lactating dairy cows. Pages 34-37 in NZ Soc. Anim. Prod. Proc. New Zealand Society of Animal Production.

Zebari, H. M. 2019. Investigations of factors that influence oestrus expression in dairy cattle. Department of Animal Production, Welfare and Veterinary Sciences, Harper Adams University.

\section{ORCIDS}

C. B. Reed $\odot$ https://orcid.org/0000-0001-7010-185X

B. Kuhn-Sherlock ㄴ https://orcid.org/0000-0002-1890-0301

C. R. Burke ๑ https://orcid.org/0000-0003-3868-8675

S. Meier (®) https://orcid.org/0000-0002-4386-7734 